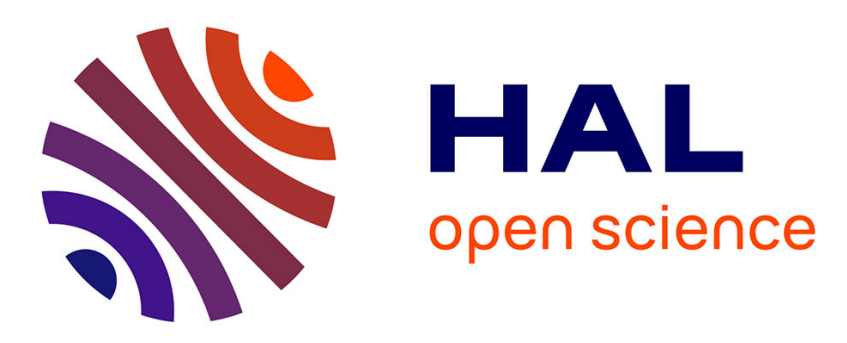

\title{
Simulating the Geological Fate of Terrestrial Organic Matter: Lignin vs Cellulose
}

Lea Atmani, Pierre-Louis Valdenaire, Roland J.-M. Pellenq, Christophe

Bichara, Henri van Damme, Adri C T van Duin, Franz Ulm, Jean-Marc

Leyssale

\section{To cite this version:}

Lea Atmani, Pierre-Louis Valdenaire, Roland J.-M. Pellenq, Christophe Bichara, Henri van Damme, et al.. Simulating the Geological Fate of Terrestrial Organic Matter: Lignin vs Cellulose. Energy \& Fuels, 2020, 34 (2), pp.1537-1547. 10.1021/acs.energyfuels.9b03681 . hal-02491070

\section{HAL Id: hal-02491070 \\ https://hal.science/hal-02491070}

Submitted on 25 Feb 2020

HAL is a multi-disciplinary open access archive for the deposit and dissemination of scientific research documents, whether they are published or not. The documents may come from teaching and research institutions in France or abroad, or from public or private research centers.
L'archive ouverte pluridisciplinaire HAL, est destinée au dépôt et à la diffusion de documents scientifiques de niveau recherche, publiés ou non, émanant des établissements d'enseignement et de recherche français ou étrangers, des laboratoires publics ou privés. 


\title{
Simulating the geological fate of terrestrial organic matter: Lignin vs Cellulose
}

\author{
Lea Atmani, ${ }^{\dagger, \ddagger}$ Pierre-Louis Valdenaire, ${ }^{\dagger}$ Roland J.-M. Pellenq, ${ }^{\dagger,}$ Christophe \\ Bichara ${ }^{\ddagger}$ Henri Van Damme, ${ }^{\dagger}$ Adri C. T. van Duin, ${ }^{\S}$ Franz J. Ulm, ${ }^{\dagger} \uparrow$ and \\ Jean-Marc Leyssale*,,,$\|$
}

$\dagger C N R S / M I T / A i x$ Marseille Univ. joint lab "MultiScale Materials Science for Energy and Environment", IRL 3466, Massachusetts Institute of Technology, 77 Massachusetts Avenue, Cambridge, MA 02139, USA

$\ddagger$ Aix Marseille Univ., CNRS, CINaM, Campus de Luminy, 13288 Marseille, France \Department of Civil and Environmental Engineering, Massachusetts Institute of Technology, Cambridge, MA 02139, USA

$\S$ Department of Mechanical and Nuclear Engineering, The Pennsylvania State University, University Park, Pennsylvania 16802, USA

|| Institut des Sciences Moléculaires, Univ. Bordeaux, CNRS UMR 5255, 351 Cours de la Libération, 33405 Talence, France

E-mail: jean-marc.leyssale@u-bordeaux.fr

\begin{abstract}
While shale gas has become a major source of energy, a more sustainable recovery requires better understanding of the gas/kerogen matrix interactions. Here we use replica exchange molecular dynamics to investigate the geological conversion of two important classes of gas-forming constituents of terrestrial organic matter: lignin and cellulose. In agreement with results from pyrolysis experiments, we show that lignin
\end{abstract}


produces twice as much kerogen and five times more methane than cellulose. In addition, while ex-cellulose kerogen is relatively stiff and almost non porous, ex-lignin kerogen, despite having very similar composition and bonding, is an order of magnitude more compliant due to the presence of large micropores. The obtained results can potentially improve the nanoscale brick of bottom-up models of shale gas recovery.

\section{Introduction}

The sudden massive extraction of shale hydrocarbons in the early 2000s has significantly and durably changed the energy and environment landscapes in countries like China or the US. ${ }^{1,2}$ Despite important environmental concerns, ${ }^{3-5}$ mostly due to the high-pressure hydraulic fracking process, ${ }^{6}$ shale gas and oil are still considered by many as promising and environment-friendly fuels, as compared for instance to coal. ${ }^{1}$ Furthermore, theoretical models have shown that non-aqueous fracturing with supercritical carbon dioxide could enhance methane recovery from gas shales while ensuring long term $\mathrm{CO}_{2}$ sequestration, resulting in a neutral or positive effect on greenhouse gases emissions. ${ }^{7,8}$

A specificity of shale reservoirs is that hydrocarbons are strongly adsorbed in the source rock porosity, preferentially within kerogen, the organic part in shale rocks. This has stimulated intense research efforts aimed at understanding the texture of shale deposits at all scales starting from the nanoscale. ${ }^{9,10}$ Unlike the minerals present in shales which have well-characterized properties, a detailed structure-property relationship for kerogen is still lacking. A very fundamental reason for that is that kerogen is an amorphous porous carbon solid formed by the geological burial of fossil organic matter (OM). As such, an impressive variability in heteroelement composition and structure can be observed depending on the nature of the $\mathrm{OM}$ and burial history. ${ }^{11}$ In addition, kerogen separation from the source rock is complex and often incomplete, making experimental characterization, especially mechanical testing, complex to achieve. It has to be specified that structure and composition are generally associated to the kerogen maturity, or in other words, the degree of advancement of 
the carbon-enrichment process. Immature kerogen has large heteroelement content, mostly hydrogen and oxygen, and is dominated by an aliphatic character whilst mature kerogen is considered as a highly aromatic carbon solid with few heteroelements.

Molecular simulation techniques are particularly relevant tools to predict materials properties at the nanoscale. Provided that accurate models of the kerogen matrices are available, properties relevant to hydrocarbon expulsion like the mechanical properties of the matrix ${ }^{12,13}$ or the adsorption and transport of hydrocarbons within kerogen porosity ${ }^{14-21}$ can be calculated and possibly integrated to larger scale models. ${ }^{22}$ The first (2D) chemical models of kerogen were large macromolecules hand-drawn on the basis of experimental data. ${ }^{23-26}$ Some of these models were then digitalized and turned into 3D atomistic representations using molecular modeling and simulation tools, ${ }^{27-29}$ allowing for the calculation of properties. Similarly, a series of macromolecules representative of various kerogen types at several maturities were constructed by Ungerer et al. ${ }^{30}$ on the basis of experimental data gathered in Ref. 31. These molecules were used to build large 3D kerogen models ${ }^{32}$ and investigate hydrocarbon adsorption and transport in many studies. ${ }^{14-18}$ An important limitation of this approach is that the macromolecules constituting the kerogen are generally of limited size, generally one to two orders of magnitude lighter than the insolubility limit, 5000-10000 Da according to Vandenbroucke and Largeau. ${ }^{11}$ This results in unrealistic swelling ratios, up to $70 \%$ as reported by Pathak et al. for methane adsorption at $35 \%$ mass ratio in a kerogen at the oil and gas windows boundary. ${ }^{17}$

An alternative approach was proposed by Bousige et al. who used the hybrid reverse Monte Carlo (HRMC) approach with a reactive force field to reconstruct realistic kerogen models aimed at reproducing the pair distribution functions measured using X-ray or Neutron diffraction for a few demineralized kerogen samples. ${ }^{12}$ Despite a slightly lower chemical accuracy, the obtained models were made of connected carbon backbones and were able to differentiate the mechanical properties of immature and mature samples. ${ }^{12}$ These models were also used to investigate adsorption and transport of hydrocarbons. ${ }^{19,20,33}$ However, the 
HRMC method is difficult to apply to kerogen. It indeed relies on the availability of accurate experimental density measurements and pair distribution functions, which are difficult to obtain, especially as demineralization is most often incomplete. Furthermore, even if it allows producing realistic structural models at a given maturity, it tells nothing about the natural maturation route or about the nature and quantity of the fluid phase produced during kerogen evolution. Some kerogen models were also produced by a simple liquid quench approach using reactive molecular dynamics (RMD) simulations ${ }^{13}$ using reactive force fields such as ReaxFF. ${ }^{34}$

Driven by the need to understand the conversion of organic wastes into energy resources (coal, biofuels, etc... $)^{35,36}$ and/or manufacturable carbons, ${ }^{37-40}$ RMD has also been extensively used in recent years to investigate the pyrolysis - at least at early stages - of various forms of organic matter, including lignin and cellulose, ${ }^{41-44}$ coals, ${ }^{45-49}$ kerogen ${ }^{50,51}$ and other fossil OM. ${ }^{52,53}$ Zheng et al. studied the early stages of cellulose pyrolysis using isothermal MD simulations and observed the quick fragmentation of the polymer into small (less than 9 C atoms) molecules, water being the most abundant. ${ }^{42}$ The same approach was applied by Zhang et al. to a softwood lignin model. ${ }^{41,43}$ They observed that above $1500 \mathrm{~K}$, the heavy compounds eventually condensate to form a solid pyrolysate (char), of which chemical nature varies significantly with temperature: $\mathrm{O} / \mathrm{C}$ and $\mathrm{H} / \mathrm{C}$ ratios decreases from 0.28 and 0.77 at $1500 \mathrm{~K}$ to 0.18 and 0.63 at $2100 \mathrm{~K}$. At this temperature the most abundant gas molecules are water, hydrogen and methane. ${ }^{41}$ ReaxFF based MD simulations were also used by Rismiller et al. to investigate the effect of humidity on the products of cellulose and lignin pyrolysis, showing an important effect, in both cases, on both the amount and nature of the solid pyrolysates. ${ }^{44}$

In all these studies, the simulations were run at very high temperatures to compensate for the short timescale accessible to MD simulations, typically of the order of a few nanoseconds. It is however unclear how the products distribution obtained at such high temperatures relates to the one of natural evolution, taking place at temperatures in the $350-500 \mathrm{~K}$ range 
over a million years timescale. In recent work, ${ }^{54}$ we have proposed to use an accelerated simulation scheme, the replica exchange molecular dynamics (REMD) method, in order to simulate a pyrolysis process at low or moderate temperature. In REMD, several replicas of the same system are simulated in parallel at different temperatures (higher or equal to the temperature of interest). Configuration exchanges between replicas are designed in order to ensure the convergence of each replica towards its own thermodynamic equilibrium while allowing for a much faster convergence of the low energy replicas. Using REMD, we have been able to simulate the complete conversion of cellulose into a mature kerogen and a fluid phase made of small molecules - mostly water and CO - under typical geological temperature and pressure $(423 \mathrm{~K}$ and $25 \mathrm{MPa})$.

In what follows we use REMD to investigate the geological degradation of lignin and cellulose, the two main cell constituents in higher plants, which represent good, yet oversimplified, proxies for type III (terrestrial) OM. A more accurate model of type III OM would require accounting for other constituents such as resins, waxes, cuticles, saps, etc..., which is far beyond the reach of the present study. We demonstrate here, however, that REMD simulations actually allows for a reasonable prediction of the relationship between the nature of the parent $\mathrm{OM}$ and the composition, structure and amount of the produced kerogens, their evolution pathways, and the produced fluids, including the amount of methane.

\section{Computational Methods}

\section{MD/REMD simulations}

The two kerogen precursors considered in this work are shown in Fig. 1. The first one (a) is a 4200 atom $\mathrm{I}-\beta$ cellulose crystal with atomic ratios $\mathrm{O} / \mathrm{C}=0.83$ and $\mathrm{H} / \mathrm{C}=1.67$. The second one (b) is constructed by packing 18 oligomers of one of the structural models of softwood lignin proposed by Crestini et al. ${ }^{55}$, reading $\mathrm{O} / \mathrm{C}=0.34$ and $\mathrm{H} / \mathrm{C}=1.11$. Both systems were placed within orthorhombic simulation cells with periodic boundary conditions. Prior 
to the REMD simulations the two systems were relaxed at $423 \mathrm{~K}$ and $25 \mathrm{MPa}$ using $\mathrm{MD}$ in the isothermal-isobaric NPT ensemble - where N, P, T stands for the number of atoms, pressure and temperature, respectively - until convergence of the volume (about 100 ps for the disordered lignin system). We note that, due to limitations in the system sizes, one of the precursors (cellulose) appears totally anisotropic and the other one (lignin) completely isotropic. While we agree that actual samples could show less contrasted textures, this should not affect much their thermodynamic behavior, which is the main focus of the present study.
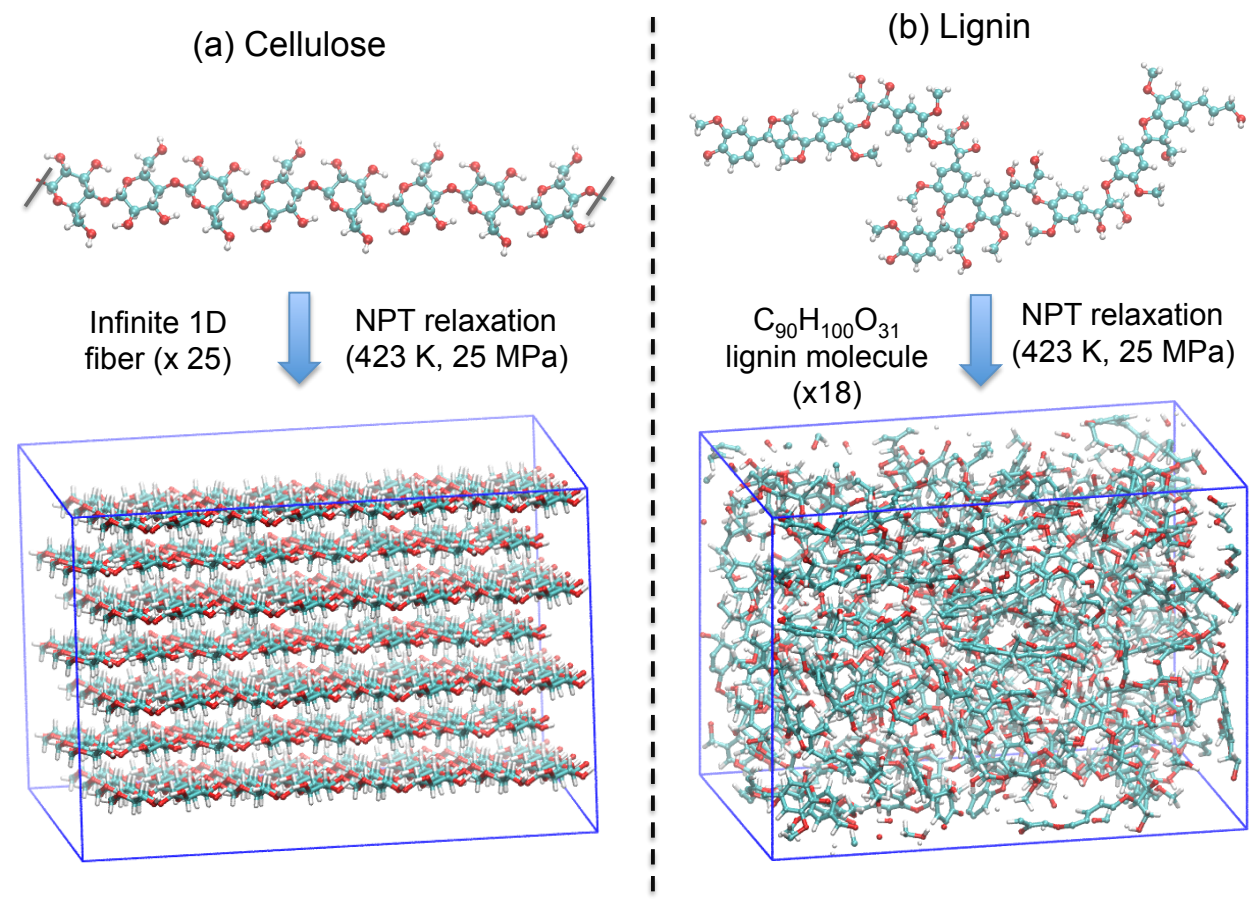

Figure 1: Representation of (a) cellulose and (b) lignin kerogen precursors. Atoms are color-coded according to carbon (cyan), oxygen (red) and hydrogen (white).

In all the simulations, interatomic interactions are accounted for using the ReaxFF potential: ${ }^{34}$ Reax2013 parameters for C-C interactions ${ }^{56}$ together with C-O, C-H, O-O, O-H and $\mathrm{H}-\mathrm{H}$ parameters from Refs 57 and 58. MD simulations are performed either in the NVT (where $\mathrm{N}, \mathrm{V}$ and $\mathrm{T}$ stands for number of atoms, volume and temperature, respectively) or NPT ensembles with Nosé-Hoover and Nosé-Hoover-Andersen thermostat and barostat, respectively. ${ }^{59}$ Time constants of 0.05 and 0.5 ps are used for temperature and pressure relaxations, respectively, and the equations of motion are integrated using a velocity-Verlet 
scheme $^{60}$ with a 0.1 fs timestep. REMD simulations use canonical (NVT) MD sampling, avoiding undesirable first order phase transition, with an exponential spacing of temperatures from the temperature of interest, $423 \mathrm{~K}$, up to $3500 \mathrm{~K}$, using 96 replicas. Replica exchanges are attempted every $10 \mathrm{fs}$; the obtained acceptance rate are of about $20 \%$. All the simulations were performed with the Large-scale Atomic/Molecular Massively Parallel Simulator (LAMMPS) package. ${ }^{61}$

An important consequence of running the simulations in the NVT ensemble is that pressure progressively increases during the run, because of fluid production. To maintain reasonable "geological" conditions, the simulations are interrupted at intervals and the replica at $423 \mathrm{~K}$ relaxed for $100 \mathrm{ps}$ at $25 \mathrm{MPa}$ in the NPT ensemble. The REMD simulation is then relaunched with all replica re-initialized with the relaxed configuration. Therefore, as the growing kerogen is maintained in contact with fluid phase at thermal and mechanical equilibrium, the reported simulations mimic confined pyrolysis experiments, which have been chosen to be the closest to natural evolution. ${ }^{62,63}$ In the case of cellulose, three relaxation stages have been necessary; ${ }^{54}$ they were performed every time the pressure was exceeding $200 \mathrm{MPa}$ for the $423 \mathrm{~K}$ replica. In the case of lignin, for simplicity, we decided to perform a relaxation run every 200 ps.

REMD simulations are performed until chemical equilibrium states are obtained at $423 \mathrm{~K}$, which takes about 750 ps for cellulose and 1300 ps for lignin. Then, after analysis, the fluid content is removed, mimicking fluid expulsion or at leat migration to larger pores, and the resulting kerogen relaxed at $423 \mathrm{~K}$ and $25 \mathrm{MPa}$ for $1 \mathrm{~ns}$. A second set of REMD simulations is finally launched to investigate whether fluid removal may, or not, induce further kerogen maturation. Those simulations are run for 1800 ps. Full atomic configurations of the different replicas are stored at intervals during the REMD processes and at the end of the pressure relaxation simulations for analysis. 


\section{Chemical analysis}

Chemical analysis is based on the identification of molecular clusters, using a standard clustering algorithm, with the following bond distance cutoffs: $1.9 \AA$ for C-C, C-O and O-O bonds, $1.5 \AA$ for $\mathrm{C}-\mathrm{H}$ bonds, $1.35 \AA$ for $\mathrm{O}-\mathrm{H}$ bonds and $1.1 \AA$ for $\mathrm{H}-\mathrm{H}$ bonds. As in former studies, ${ }^{46-48,50,64}$ the obtained molecules were classified according to four categories based on their number of $\mathrm{C}$ atoms: gas up to $4 \mathrm{C}$ atoms, light tar (oil) from 5 to $13 \mathrm{C}$ atoms, heavy tar from 14 to 40 atoms and char (or kerogen) for more than 40 atoms. Note that it leads to some re-interpretation of the results in Atmani et al. ${ }^{54}$ in which only two categories were considered (fluid below $12 \mathrm{C}$ atoms and solid at 12 and more $\mathrm{C}$ atoms).

\section{Structural analysis}

The obtained char structures are analyzed according to their $\mathrm{H} / \mathrm{C}$ and $\mathrm{O} / \mathrm{C}$ atomic ratios, the coordination numbers of the $\mathrm{C}$ atoms and the radial distribution functions. Their mediumrange order is characterized through the ring contents, identified using the shortest path ring analysis, ${ }^{65}$ the size of ring clusters and the size of (aliphatic) chains. These properties are computed by considering $\mathrm{C}$ and $\mathrm{O}$ atoms only. The accessible porosity to a methane molecule was computed by sampling the possibility of inserting a methane molecule within the matrix using a grid of $0.1 \AA$ lattice spacing. A hard-sphere non-overlap criterion between methane and the matrix atoms was adopted with usual diameters: $\sigma_{C H_{4}}=3.73 \AA, \sigma_{C}=$ $3.36 \AA, \sigma_{O}=3.17 \AA$ and $\sigma_{H}=2.42 \AA$. Pore size distributions are determined using the method schematized in Fig. 2.

At each grid point $R_{g}$ previously identified as belonging to an accessible pore, the pore size is determined using the following method inspired by Gelb and Gubbins ${ }^{66}$

1. A position $\mathbf{R}_{\mathbf{p}}$ is chosen at random within a sphere of diameter $D_{\max }$ larger than the expected maximum pore size (a large value of $3 \mathrm{~nm}$ was adopted).

2. Determine the shortest distance between $\mathbf{R}_{\mathbf{p}}$ and the van der Waals surface of a matrix 


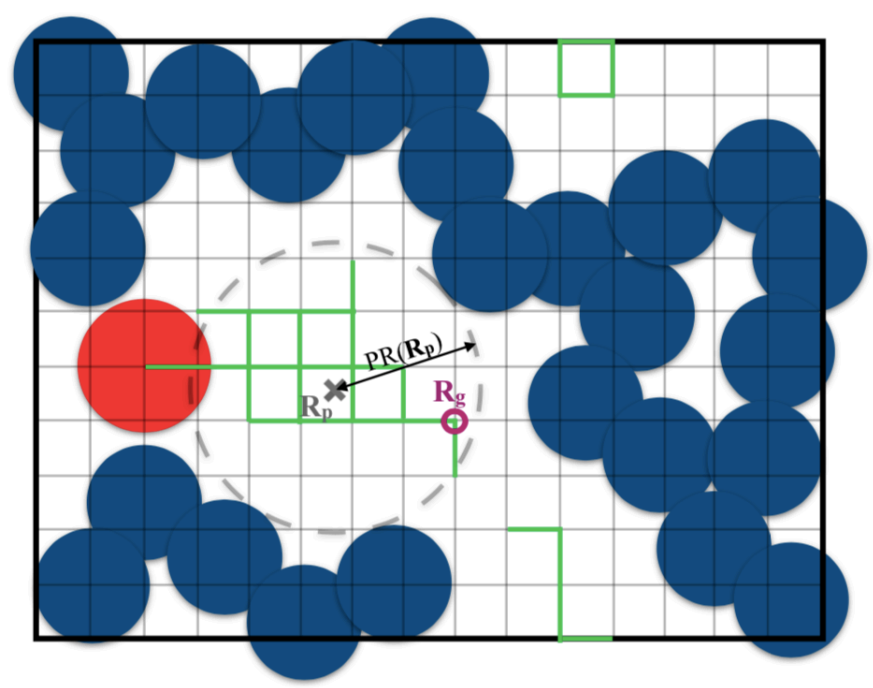

Figure 2: 2D scheme illustrating the determination of pore sizes on a grid (represented by grey lines). Blue spheres are the matrix atoms and the red sphere represents a probe (methane) molecule in the porosity. Green lines represent the lattice points accessible to the probe. $R_{g}$ is the grid point at which the pore size is under evaluation and $R_{p}$ is the center of the largest spherical pore containing $R_{g}$. A coarse grid spacing has been chosen in the schematics, for clarity.

atom, defining the radius of the largest spherical pore centered on $\mathbf{R}_{\mathbf{p}}$ :

$$
\operatorname{PR}\left(\mathbf{R}_{\mathbf{p}}\right)=\min \left(\left\|\mathbf{R}_{\mathbf{p}}-\mathbf{R}_{\mathbf{i}}\right\|-\frac{1}{2} \sigma_{i}\right)
$$

where $i$ runs over the $N$ atoms of the kerogen matrix and $\mathbf{R}_{\mathbf{i}}$ and $\sigma_{i}$ are the position and van der Waals diameter of atom $i$, respectively.

3. Check whether the considered grid point (located at $\mathbf{R}_{\mathbf{g}}$ ) belongs to the same pore $\left(\left\|\mathbf{R}_{\mathbf{p}}-\mathbf{R}_{\mathbf{g}}\right\|<\operatorname{PR}\left(\mathbf{R}_{\mathbf{p}}\right)\right)$. If yes, store the pore diameter $\left.\mathrm{PD}=2 \mathrm{PR}\left(\mathbf{R}_{\mathbf{p}}\right)\right)$.

4. Repeat the process until 500 such pore sizes are obtained, eventually decrease progressively $D_{\max }$ in case of low success ratio at step 3 . A good estimate of the pore size at $\mathbf{R}_{\mathbf{g}}$ is given by the maximum value of the obtained pore diameters.

The pore size distribution (PSD) is then obtained by creating an histogram over the estimated pore diameters at the different grid points. Note that we consider only pore sizes larger than 
the diameter of a methane molecule $\sigma_{\mathrm{CH}_{4}}$.

\section{Results}

The evolutions with REMD time of the fractions of gas $\left(\mathrm{C}_{0-4}\right)$, oil $\left(\mathrm{C}_{5-13}\right)$, tar $\left(\mathrm{C}_{14-40}\right)$ and char $\left(\mathrm{C}_{40+}\right)$ obtained for the replicas at $423 \mathrm{~K}$ and $25 \mathrm{MPa}$ are shown in Fig. 3(a) and 3(b) for cellulose and lignin, respectively. Note that even though time in REMD simulations has no physical reality, it can still be used as a metric, just like Monte Carlo steps in a Metropolis Monte Carlo simulation, to trace the evolution of a replica towards its equilibrium state. Also note that all the data reported in Figures 3-7 correspond to the initial REMD simulations (i.e. prior to fluid expulsion), so that the data correspond to confined pyrolysis experiments. The results are compared to available measurements obtained with open pyrolysis experiments at higher temperatures and for, obviously, shorter times. We assume here that the difference in pyrolysis conditions (temperature, time and confinement) are of second order with respect to the dependence of the fluid composition on the nature and composition of the OM.

As observed for reactive MD simulations at much higher temperatures, ${ }^{42,67}$ cellulose entirely disintegrates into small molecules, mostly light tar molecules, in the very early stages of the REMD simulation (Fig. 3(a)). These molecules further react to form even smaller (gas) species which dominate in mass after $\sim 100$ ps. Then kerogen starts growing. Above 600 ps the system reaches an equilibrium state made of $\sim 68$ and 27 mass $\%$ of gas and kerogen, respectively. The transformation of lignin follows a similar path (Fig. 3(b)). However, because of the difference in composition of the two systems, lignin produces a significantly higher fraction of char (around 58 mass \%) and a significantly lower fraction of gas (41 mass \%). Also, whilst some traces of light tar are still visible in the ex-cellulose system at equilibrium, lignin is almost entirely decomposed into char and gas. These differences of char and volatile yields between cellulose and lignin agree well with those reported in recent

experimental pyrolysis studies et al. ${ }^{68-70}$ More precisely, Qu et al. ${ }^{68}$ obtained char yields of 

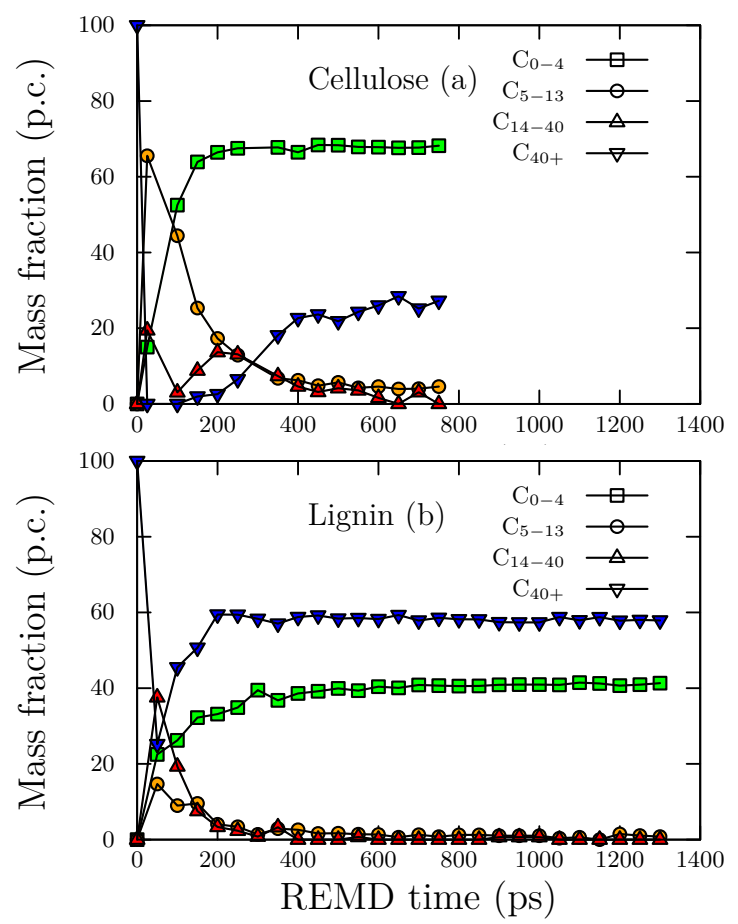

Figure 3: Evolution with REMD time of the mass fractions of gas $\left(\mathrm{C}_{0-4}\right)$, light tar $\left(\mathrm{C}_{5-13}\right)$, heavy tar $\left(\mathrm{C}_{14-40}\right)$ and char $\left(\mathrm{C}_{40+}\right)$ for cellulose $(\mathrm{a})$ and lignin (b) at $423 \mathrm{~K}$ and $25 \mathrm{MPa}$.

28 and 69 wt. \% for cellulose and lignin respectively, in fast pyrolysis experiments at $350^{\circ} \mathrm{C}$. They observed that the char yields slightly decrease down to 13 (cellulose) and 40 (lignin) wt. $\%$ upon increasing the pyrolysis temperature to $650^{\circ} \mathrm{C}$. Muley et al. ${ }^{69}$ found char yields of around 22 and 55 wt. \% for cellulose and lignin, respectively, with very limited temperature dependence in the $500-700^{\circ} \mathrm{C}$ range. Finally, Gagíc et al. ${ }^{70}$ obtained char yields of about 25 wt. \% in hydrothermal pyrolysis of cellulose at temperatures in the $250-300{ }^{\circ} \mathrm{C}$ range.

We now describe in more details the content of the fluid phase at equilibrium and its evolution during the simulations. Fig. 4 shows the distributions in mass of the fluid phase according to $\mathrm{n}_{C}$, the number of $\mathrm{C}$ atoms in the molecules, as obtained at the end of the REMD simulations. We note that at equilibrium, no heavy tar species $\left(\mathrm{n}_{C}>13\right)$ are obtained for both systems, even though this does not exclude heavy tar formation from more realistic models of type III OM. As shown in Fig. 4, about $90 \%$ of the fluid mass is composed by molecules with $\mathrm{n}_{C}=0$ or 1 and about $95 \%$ by molecules with $\mathrm{n}_{C} \leq 2$. Following this 


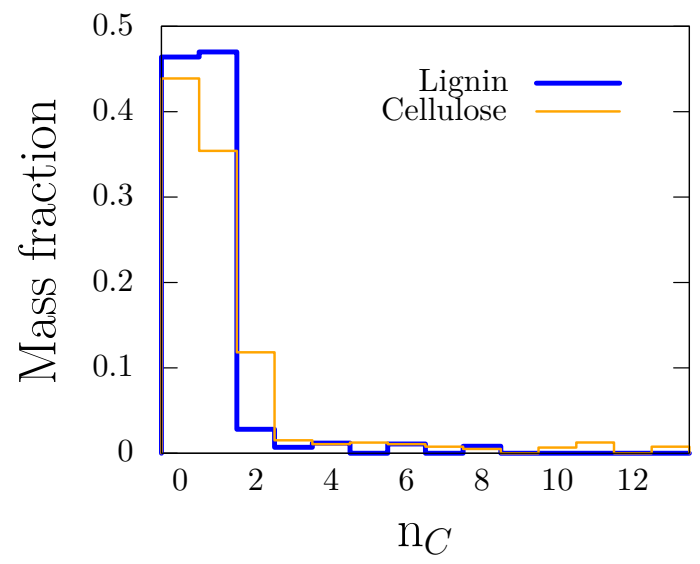

Figure 4: Distribution in mass of the fluid $\left(\mathrm{C}_{0-40}\right)$ phases at equilibrium as a function of the number of $\mathrm{C}$ atoms. Data corresponds to the replica at $423 \mathrm{~K}$ and $25 \mathrm{MPa}$ after $1300 \mathrm{ps}$ and 750 ps of REMD for lignin and cellulose, respectively.

result, we show in Fig. 5, 6 and 7, the obtained evolutions with REMD time of the yields of inorganic $\left(\mathrm{C}_{0-1}\right)$ molecules, $\mathrm{C}_{1}$ organic molecules and $\mathrm{C}_{2}$ organic molecules, respectively.

Water is by far the most abundant pyrolysis product amongst the fluid phase (Fig. 5). Its yield at equilibrium is about twice as large with cellulose than with lignin. CO is the second most produced compound and, again, most abundant by a 2:1 ratio with cellulose than with lignin. $\mathrm{H}_{2}$ and $\mathrm{CH}_{4}$ are third and fourth in abundance at equilibrium, respectively. One note that, unlike the three other mentioned species, the methane yield is about five times larger with lignin than with cellulose (Fig. 6), in agreement with results from Qu et al. ${ }^{68}$ A simple interpretation of this result can be conceived as follows: Assuming that oxygen serves to form inorganic volatiles, mostly $\mathrm{H}_{2} \mathrm{O}$, that the remaining hydrogen atoms serve to form $\mathrm{CH}_{4}$ and considering the initial $\mathrm{H} / \mathrm{C}$ and $\mathrm{O} / \mathrm{C}$ ratios of the two precursors, one easily sees that after dehydration the $\mathrm{H} / \mathrm{C}$ ratio is much higher in the ex-lignin material than in the ex-cellulose material. The former can thus release a much larger amount of methane. Furthermore, we note that methane is by far the most abundant hydrocarbon obtained in both systems, in good correlation with results from pyrolysis experiments. ${ }^{68,71,72}$ However, because of the small system sizes considered here, we cannot provide any meaningful statistical data for larger alkanes (actually no other alkane was present at equilibrium for both systems). 

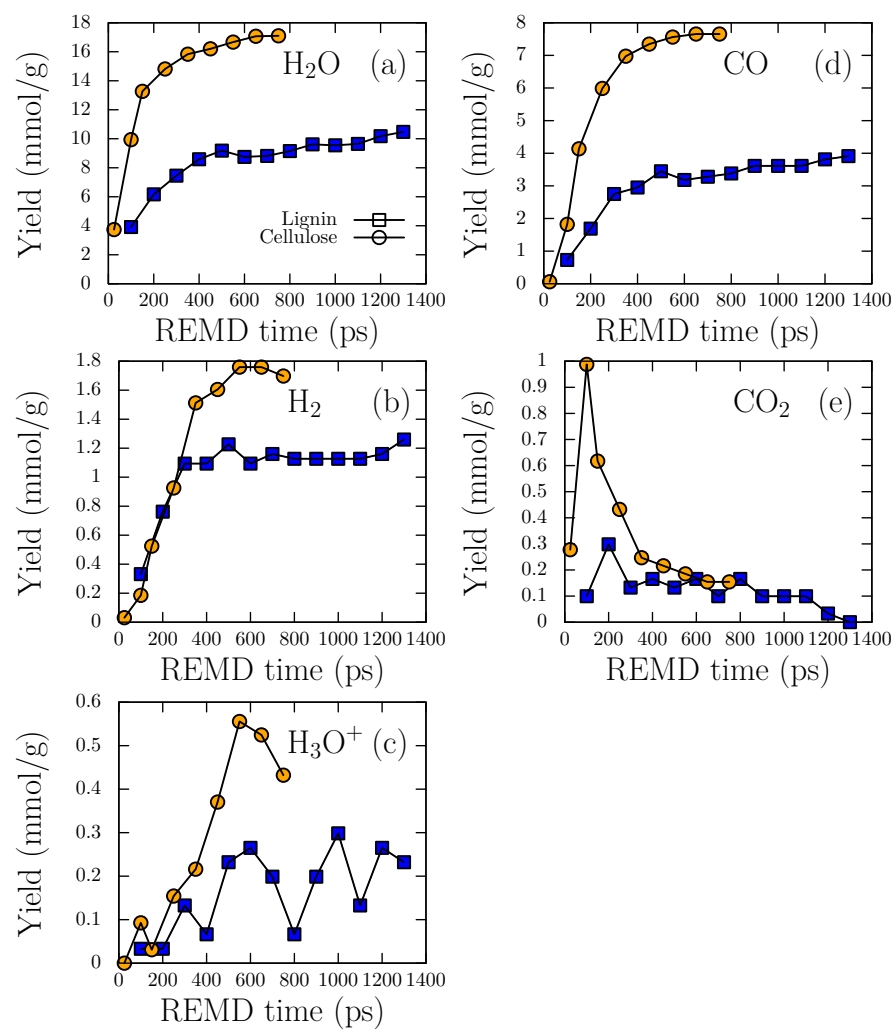

Figure 5: Evolution with REMD time of the mass fractions of inorganic gas for cellulose and lignin precursors at $423 \mathrm{~K}$ and $25 \mathrm{MPa}$ : (a) $\mathrm{H}_{2} \mathrm{O}$, (b) $\mathrm{H}_{2}$, (c) $\mathrm{H}_{3} \mathrm{O}^{+}$, (d) $\mathrm{CO}$ and (e) $\mathrm{CO}_{2}$. 

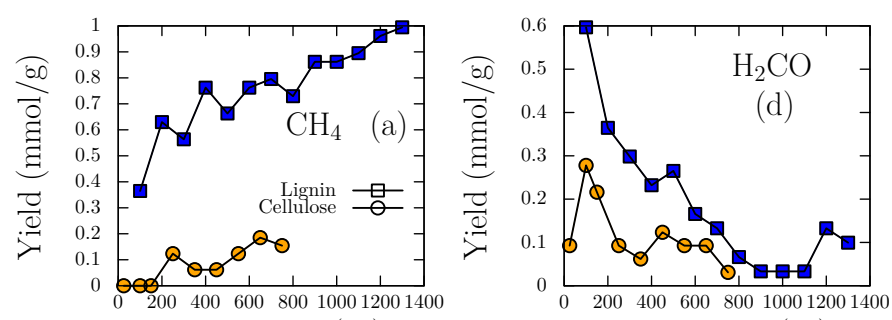

REMD time (ps)

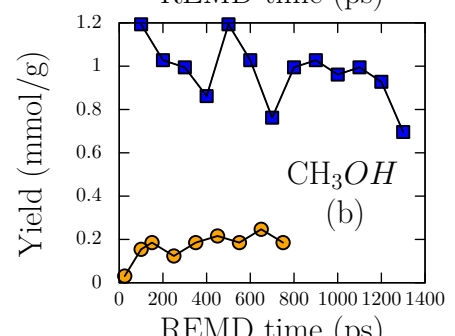

REMD time (ps)
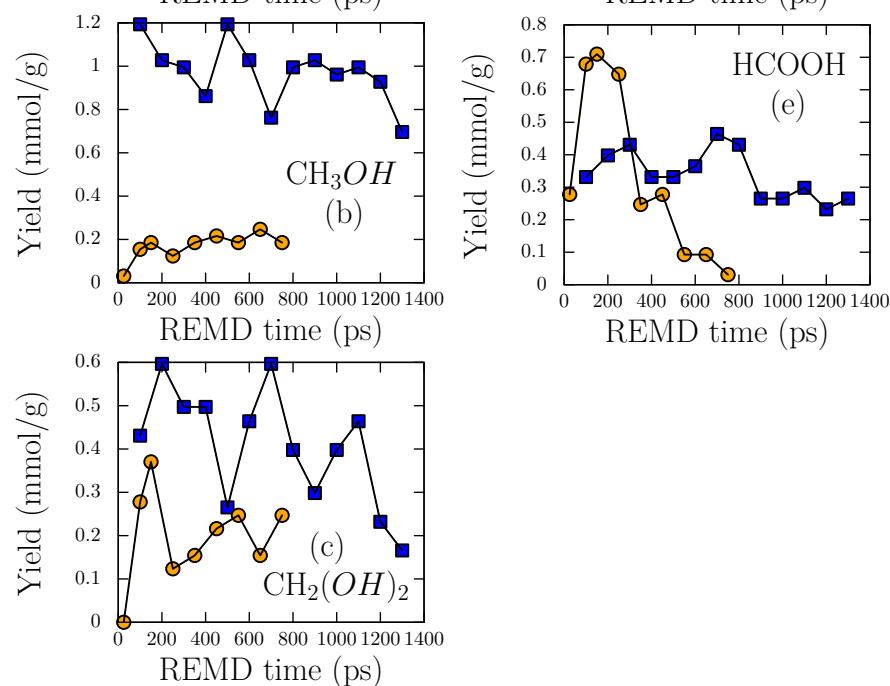

REMD time (ps)

Figure 6: Same as Fig. 5 for $\mathrm{C}_{1}$ hydrocarbons: (a) $\mathrm{CH}_{4}$, (b) $\mathrm{CH}_{3}(\mathrm{OH})$, (c) $\mathrm{CH}_{2}(\mathrm{OH})_{2}$, (d) $\mathrm{H}_{2} \mathrm{CO}$ and (e) $\mathrm{HCOOH}$. 
Even though we do not expect a perfect correlation between the fluid phase obtained after geological burial, supposedly at, or close to, thermodynamic equilibrium, ${ }^{73}$ and those obtained after pyrolysis experiments, which may depend significantly on thermal history, the results obtained in this work agree well with some experimental and theroetical reports on cellulose/lignin pyrolysis. Indeed, in most studies water, $\mathrm{CO}_{2}, \mathrm{H}_{2}, \mathrm{CO}$ and $\mathrm{CH}_{4}$ are the main produced volatiles. ${ }^{68,71,72}$ In the present work, $\mathrm{CO}_{2}$ mostly appears as an intermediate at short simulation times. As discussed in Ref. 54, the formation energy of $\mathrm{CO}_{2}$ is significantly overestimated by the version of ReaxFF used in this work, which was essentially developed to account for solid carbon phases. Hence, $\mathrm{CO}_{2}$ is less stable than it should be and is quickly consumed after formation to produce more stable species. Its equilibrium yield is thus significantly underestimated in our simulations.

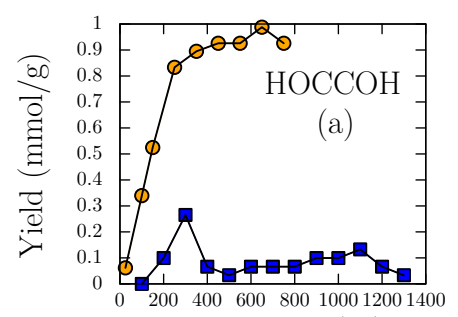

REMD time (ps)

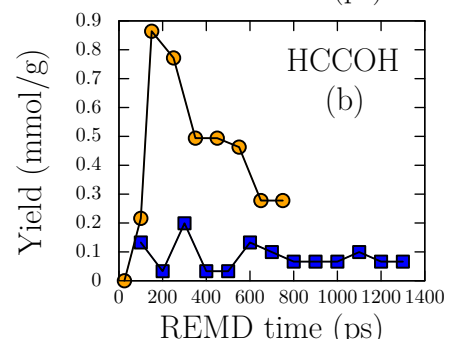

REMD time (ps)

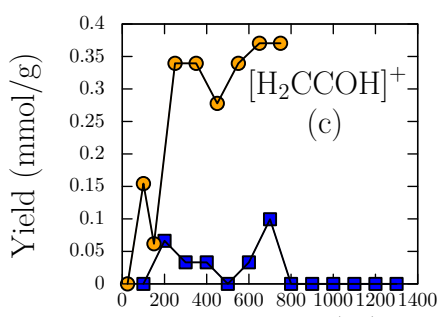

REMD time (ps)

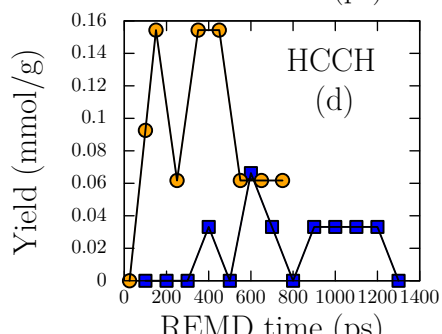

REMD time (ps)

Figure 7: Same as Fig. 5 for $\mathrm{C}_{2}$ hydrocarbons: (a) $\mathrm{HOCCOH}$, (b) $\mathrm{HCCOH}$, (c) $\mathrm{H}_{2} \mathrm{CCOH}^{+}$ and (d) $\mathrm{HCCH}$.

In addition to methane, other produced $\mathrm{C}_{1}$ species include, by order of importance, methanol, formic acid, methanediol and formaldehyde (Fig. 6). Interestingly, while the yields of inorganic gases were always larger for cellulose than for lignin, for all $\mathrm{C}_{1}$ species the obtained yields are much higher with lignin than with cellulose. Also, while some species can be definitively qualified as products - this is the case of $\mathrm{CH}_{4}, \mathrm{CH}_{3} \mathrm{OH}$ and $\mathrm{CH}_{2}(\mathrm{OH})_{2}$, 
others like $\mathrm{H}_{2} \mathrm{CO}$ and, to a lesser extent, $\mathrm{HCOOH}$, are most likely intermediates that are produced, then consumed during the simulations.

Finally, the yields of the four most abundant $\mathrm{C}_{2}$ species - acetylenediol (HOCCOH), ethynol $(\mathrm{HOCCOH})$, ketenium $\left(\mathrm{H}_{2} \mathrm{CCOH}^{+}\right)$and acetylene $(\mathrm{HCCH})$ are shown in Fig. 7. First, we observe that all these compounds mostly appear during the conversion of cellulose and very little in the case of lignin, indicating a strong correlation with the chemical nature of the precursor. In addition, the three neutral compounds are acetylenic compounds, which are not expected from cellulose pyrolysis. It was shown in Ref. 54 that their formation energies are relatively well accounted for by the ReaxFF forcefield, even though a little overstabilized with respect to DFT. However, as shown in Ref. 54 both hydronium (Fig. 5) and ketenium (Fig. 7) are severely over-stabilized by ReaxFF due to a very large, artificial, charge transfer. Charges on these ions were found to be only of $+0.34 e$ and $+0.13 e$ for hydronium and ketenium respectively. The production of these two species in such quantities can thus be considered as an artifact.

Evolutions of the kerogen phases during the REMD simulations are shown under the form of a van Krevelen diagram in Fig. 8. Both precursors follow the almost exact same path, which is found within the reported data cloud for type III OM. ${ }^{11}$ We observe that, in purely confined pyrolysis conditions, the ex-cellulose kerogen ends up its decomposition process at values of 0.55 and 0.04 for $\mathrm{H} / \mathrm{C}$ and $\mathrm{O} / \mathrm{C}$, respectively. These values are significantly higher than those obtained for ex-lignin kerogen: $0.5(\mathrm{H} / \mathrm{C})$ and $0.01(\mathrm{O} / \mathrm{C})$. However, by releasing the fluid content and repeating the REMD process, the ex-cellulose kerogen eventually reaches the same final composition as the ex-lignin kerogen, which typically corresponds to a mature type III kerogen at the end of catagenesis. ${ }^{11}$ It is noticeable that the final $\mathrm{O} / \mathrm{C}$ values are slightly lower than those obtained for actual natural samples, ${ }^{24,31,63}$ which may result from the fact that the simple precursors considered here cannot fully account for type III OM, and especially to the presence of aliphatic compounds within it. For the same reason, the simulations seem to underestimate $\mathrm{H} / \mathrm{C}$ at large $\mathrm{O} / \mathrm{C}$. 


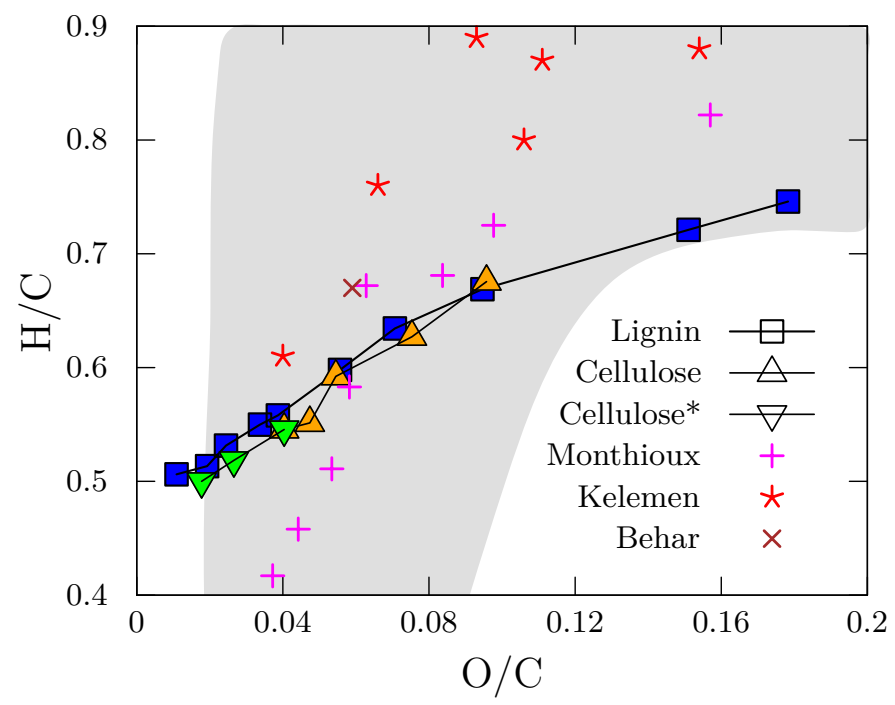

Figure 8: Van Krevelen diagram comparing the evolution of ex-lignin (squares) and excellulose (triangles) kerogen to confined pyrolysis experiments on fossil type III OM by Monthioux et al. ${ }^{63}$ and to natural samples analyzed by Kelemen et al. ${ }^{31}$ and Béhar and Vandenbroucke. ${ }^{24}$ The shaded area roughly indicates the spread of natural samples of type III OM. ${ }^{11}$ Yellow triangles: First REMD simulation; green triangles: Second REMD simulation (after fluid release and relaxation).

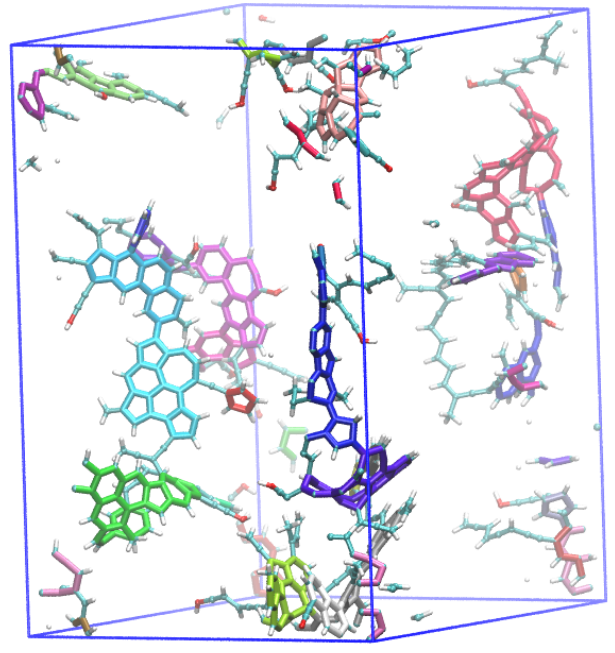

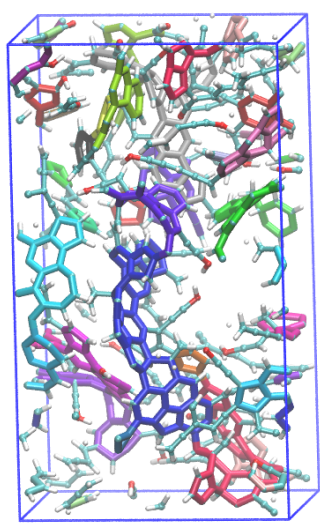

(b)

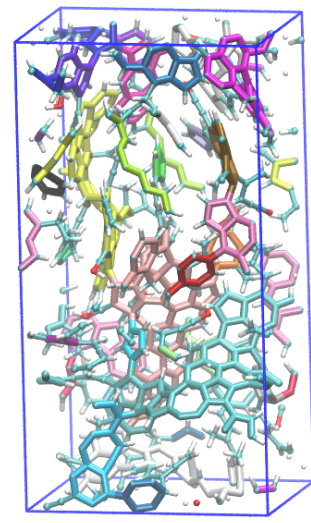

(c)

(a)

Figure 9: Ex-cellulose kerogen obtained (a) at the end of the first REMD simulation, (b) after fluid removal and NPT relaxation and (c) after the second REMD simulation and NPT relaxation. Ball and stick representations are shown with the following color code: $\mathrm{C}$ (cyan), $\mathrm{O}$ (red) $\mathrm{H}$ (white); ring clusters are displayed with larger sticks, one color per cluster. Note that only the solid part (kerogen) is displayed for clarity, especially in Fig. 9(a). 
Snapshots of the kerogen models obtained from cellulose and lignin, shown in Fig. 9 and Fig. 10, respectively, unravel slightly different mechanisms for the kerogen growth. As shown in Fig. 9(a), at the end of the $1^{\text {st }}$ REMD process, the ex-cellulose kerogen is made of two independent molecules $\left(\mathrm{C}_{434} \mathrm{H}_{229} \mathrm{O}_{16}\right.$ and $\left.\mathrm{C}_{235} \mathrm{H}_{136} \mathrm{O}_{11}\right)$ dispersed in a large amount of fluid. We would expect a phase separation to occur between the fluid, and especially its hydrophilic content, and the kerogen. However, as discussed in Ref. 54, this is unlikely to happen in such a small volume. In the present state, the kerogen does not have any mechanical properties or defined porosity. After total fluid release and relaxation at $25 \mathrm{MPa}$ (Fig. 9(b)), the kerogen condensates into a dense state $\left(1.32 \mathrm{~g} / \mathrm{cm}^{3}\right)$ with $13 \%$ porosity (accessible to methane) and a bulk modulus of $2 \mathrm{GPa}$. During the $2^{\text {nd }}$ REMD, in addition to releasing a few extra fluid molecules $\left(10 \mathrm{H}_{2} \mathrm{O}, 6 \mathrm{CO}\right.$ and $\left.5 \mathrm{H}_{2}\right)$, the two molecules of the kerogen merge to form a unique, percolating, solid-like species $\left(\mathrm{C}_{669} \mathrm{H}_{365} \mathrm{O}_{27}\right)$. The final density, porosity and bulk modulus are $1.26 \mathrm{~g} / \mathrm{cm}^{3}, 7 \%$ and $8 \mathrm{GPa}$, respectively.

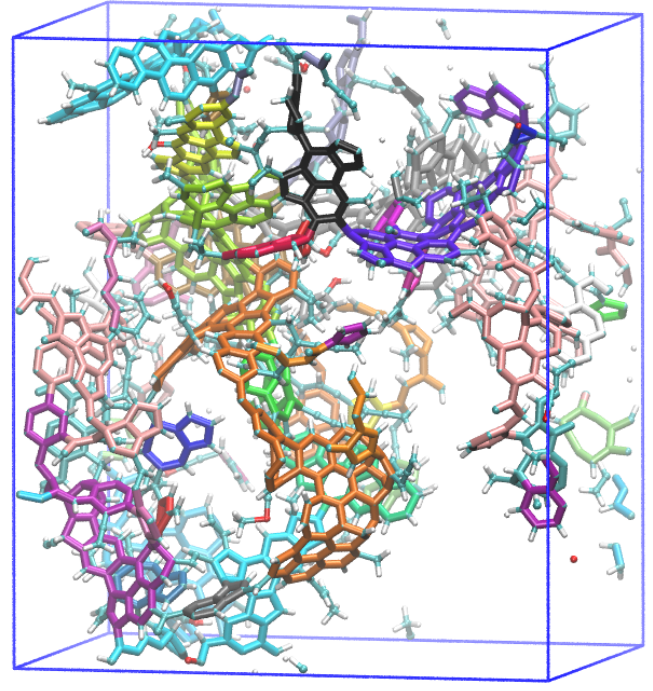

(a)

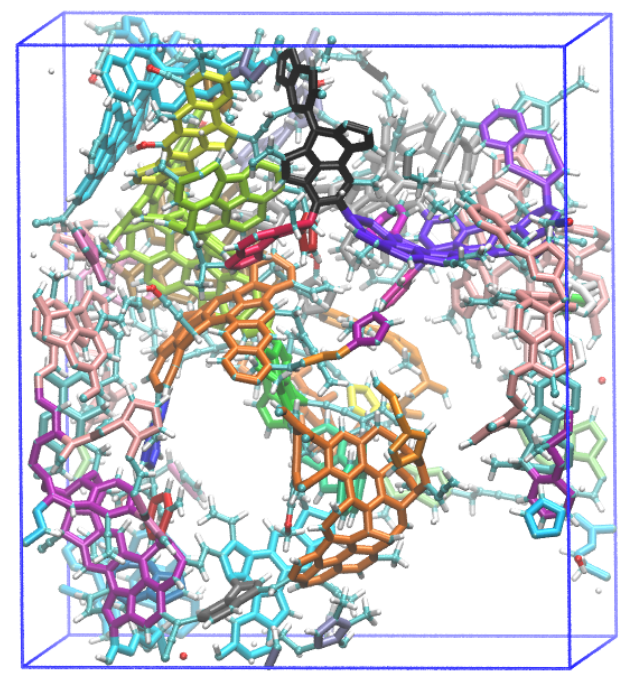

(b)

Figure 10: Same as Fig. 9 for the ex-lignin kerogen. (a) end of the first REMD simulation; (b) after fluid removal and NPT relaxation.

The ex-lignin kerogen model is shown in Fig. 10. At the end of the REMD process it is composed of a unique, percolating, fragment of composition $\mathrm{C}_{1377} \mathrm{H}_{697} \mathrm{O}_{15}$. Compared to 
cellulose where the coalescence of kerogen fragments appears at a late stage of the kerogen evolution $(\mathrm{H} / \mathrm{C}<0.55)$ and after fluid expulsion, in the case of lignin the kerogen is found under the form of a unique fragment, enclosing the produced fluid within relatively large micropores, as early as $\mathrm{H} / \mathrm{C} \sim 0.67$. Removing the fluid and relaxing the kerogen under geological $\mathrm{T}$ and $\mathrm{P}$ leads to $\mathrm{a} \sim 18 \%$ contraction of the volume, indicating a high compressibility of the structure. This is confirmed by a bulk modulus of $0.7 \pm 0.1 \mathrm{GPa}$ and an important accessible porosity $(45 \%)$ corresponding to a low density of $0.86 \mathrm{~g} / \mathrm{cm}^{3}$. As for cellulose, a second REMD process was launched after fluid release and relaxation. Despite 1800 ps of simulation, no significant change in the kerogen was observed. Results from this second simulation will not be discussed further in what follows.
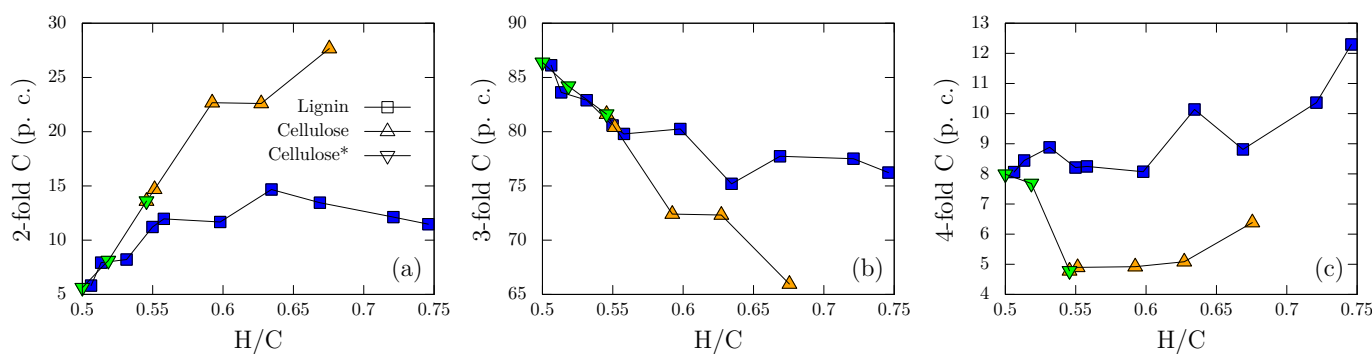

Figure 11: Evolutions of the fractions of (a) two-fold, (b) three-fold and (c) four-fold C atoms with $\mathrm{H} / \mathrm{C}$ ratio for ex-lignin (squares) and ex-cellulose (triangles) kerogen. Yellow triangles: First REMD simulation; green triangles: Second REMD simulation (after fluid removal).

We now describe further the structure of the kerogen models and their evolution during growth and maturation as measured by a decreasing $\mathrm{H} / \mathrm{C}$ ratio. Fig. 11 shows the evolutions of the $\mathrm{C}$ atoms coordination numbers, related to the fraction of $\mathrm{sp}, \mathrm{sp}^{2}$ and $\mathrm{sp}^{3}$ hybridizations. At equilibrium, very similar coordination numbers are obtained for both models, with $86 \%$ of three-fold $\left(\mathrm{sp}^{2}\right)$ atoms, $8 \%$ of four-fold $\left(\mathrm{sp}^{3}\right)$ atoms and $5 \%$ of two-fold (sp or radical $\mathrm{sp}^{2}$ ) atoms. The fraction of three-fold atoms continuously increases during kerogen evolution $(i$. e., while $\mathrm{H} / \mathrm{C}$ decreases $)$. In the early stages $(\mathrm{H} / \mathrm{C}>0.55)$ one note that the fractions of two-fold atoms is lower for the ex-lignin kerogen than for the ex-cellulose kerogen. Conversely the fractions of four-fold atoms are higher.

Fig. 12 gives some information on the medium-range order of the evolving kerogen 

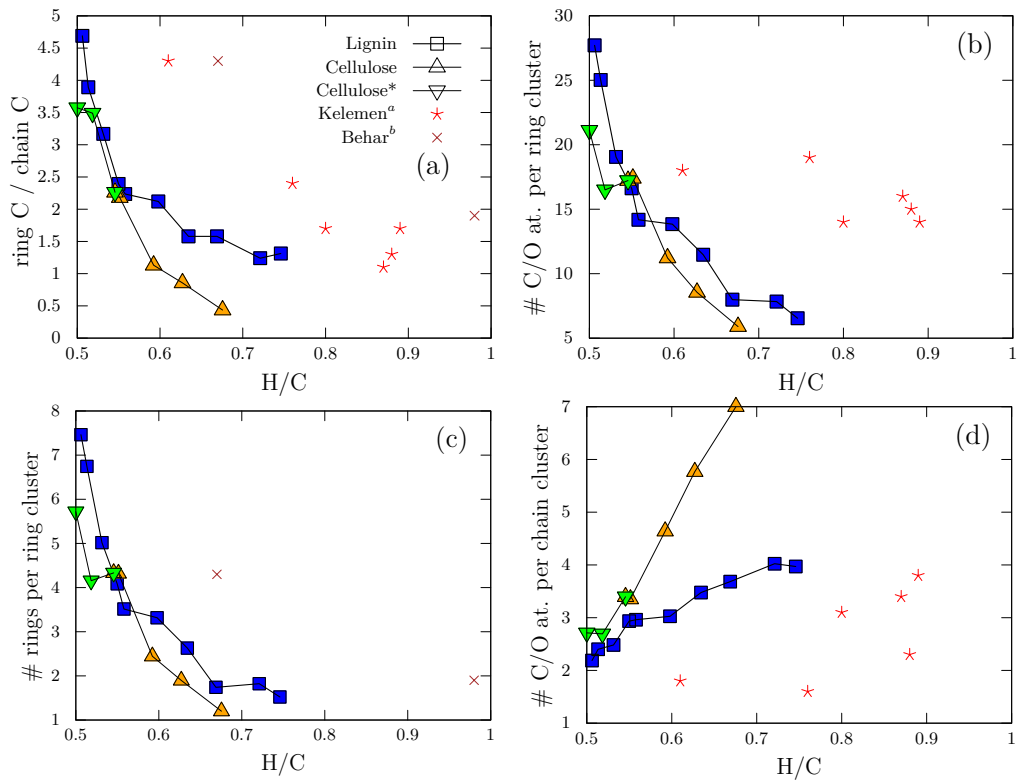

Figure 12: Evolutions with the $\mathrm{H} / \mathrm{C}$ ratio of (a) the ratio of $\mathrm{C}$ atoms in rings or chains, (b) the average number of heavy atoms per (b) ring cluster, (c) the average number of rings per ring cluster, and (d) the average number of heavy atoms per chain cluster. Literature data from experimental analysis of type III $\mathrm{OM}^{24,31}$ are included for comparison. Blue squares: ex-lignin kerogen $\left(1^{\text {st }}\right.$ REMD); Triangles: ex-cellulose kerogen (yellow: $1^{\text {st }}$ REMD; green: $2^{\text {nd }}$ REMD); Red stars: data from Kelemen et al.;13 Brown crosses: data from Behar and Vandenbroucke. ${ }^{24}$ 
models. The ratio of carbon atoms in rings with respect to carbon atoms in chains (Fig. 12(a)) progressively evolves from around 1 at high $\mathrm{H} / \mathrm{C}$ to about 4 at $\mathrm{H} / \mathrm{C}=0.5$. One note that for $\mathrm{H} / \mathrm{C}<0.55$, the two models follow the same curve, as already observed for the $\mathrm{sp}^{2}$ fraction (Fig. 11(b)). Similarly, the number of heavy atoms (C or O) per ring cluster, shown in Fig. 12(b) increases from about 6 (1 ring) at $\mathrm{H} / \mathrm{C} \sim 0.7$, to around 25, corresponding to about 7 rings (see Fig. $12(\mathrm{~d})$ ) at $\mathrm{H} / \mathrm{C}=0.5$, marking the growth of aromatic domains during kerogen evolution. As shown in Fig. 12(d), the average number of heavy atoms per chain cluster decreases down to 2.1 and 2.7 for the ex-lignin and ex-cellulose kerogen, respectively. This clearly highlights a very low aliphatic content in such mature type III kerogen. One note that at lower maturities, the average chain size is significantly larger for the ex-cellulose kerogen than for the ex-lignin kerogen. For instance, chain clusters count on average 7 heavy atoms at a $\mathrm{H} / \mathrm{C}$ value of 0.67 for ex-cellulose kerogen, which is twice as much as for ex-lignin kerogen at the same maturity. Comparing now the simulation results to available experimental data on type III OM from Refs. 24 and 31, also shown in Fig. 12 , one can notice that the structural parameters obtained in simulations have very similar values to those derived from experiments, albeit with a slight shift of the simulation data towards low $\mathrm{H} / \mathrm{C}$ values.
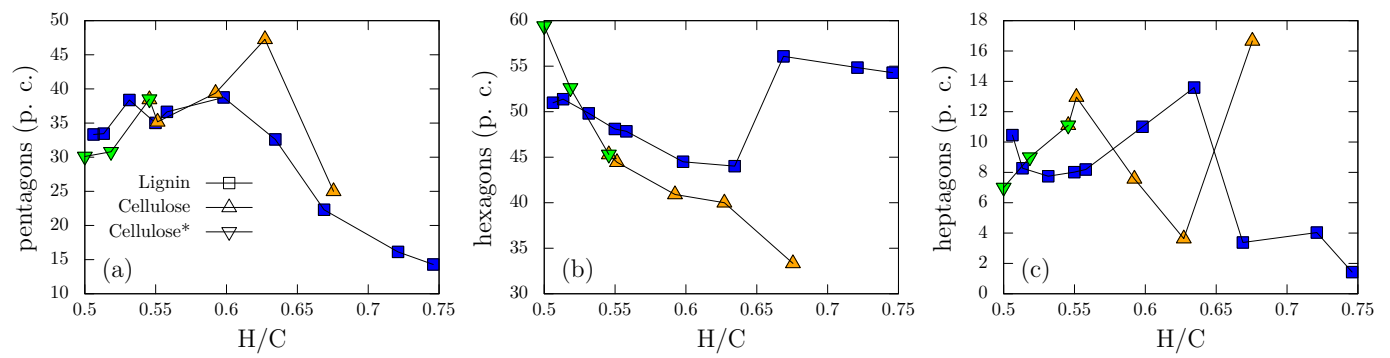

Figure 13: Evolutions of the fractions of (a) pentagonal, (b) hexagonal and (c) heptagonal rings with $\mathrm{H} / \mathrm{C}$ ratio for ex-lignin (squares) and ex-cellulose (triangles) kerogen. Yellow triangles: First REMD simulation; green triangles: Second REMD simulation (after fluid removal).

Fig. 13 shows the distributions of rings within the kerogen models. At equilibrium, the two kerogen models show similar ring statistics with 50-60\% of hexagons, 30-35\% of 
pentagons and around $10 \%$ of heptagons. This particular distribution, with a much higher fraction of pentagons than heptagons is indicative of curved, fullerene-like, layers, which is consistent with the snapshots given in Fig. 9 and Fig. 10. No particular evolution of the ring statistics with $\mathrm{H} / \mathrm{C}$ can be detected in Fig. 13. We note that the high fraction of nonhexagonal rings, especially pentagons, is consistent with the highly disordered arrangement of 002 carbon lattice fringe images recorded by Oberlin et al. for mature type III kerogen. ${ }^{23}$
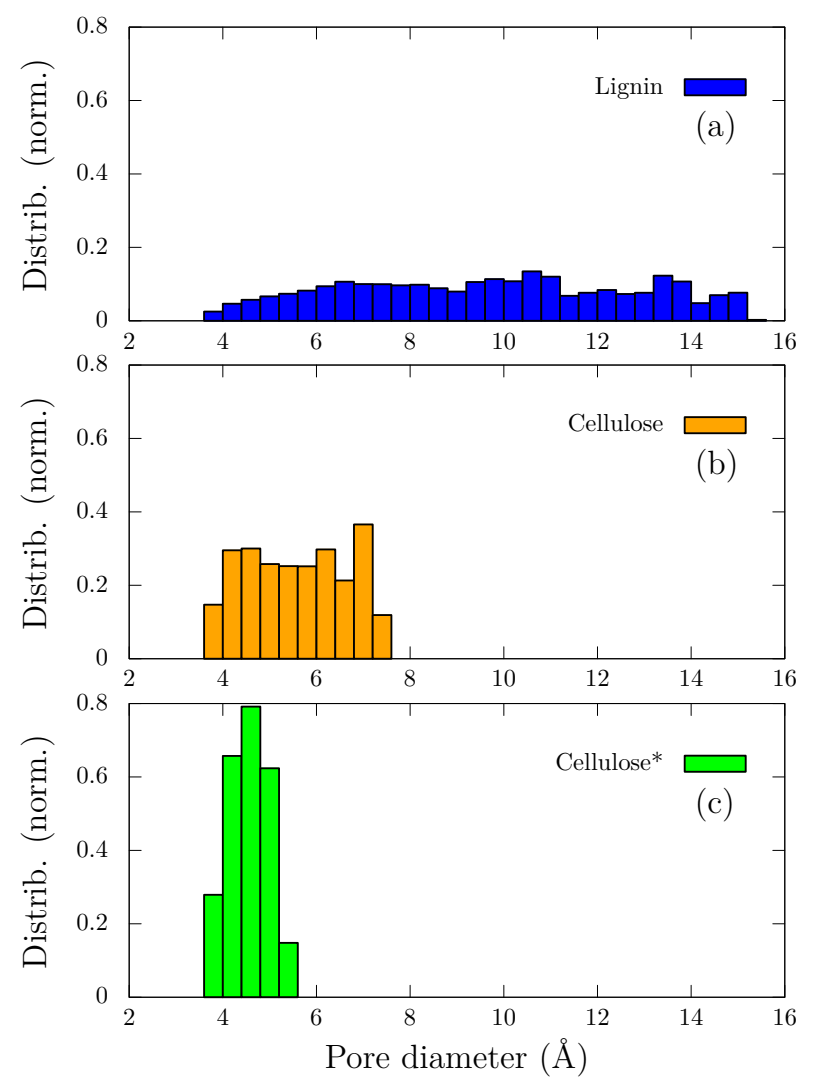

Figure 14: Normalized pore size distributions of (a) the ex-lignin model at $\mathrm{H} / \mathrm{C}=0.5$, (b) the ex-cellulose kerogen model at $\mathrm{H} / \mathrm{C}=0.55$ and $(\mathrm{c})$ the ex-cellulose model at $\mathrm{H} / \mathrm{C}=0.5$.

Finally, Fig. 14 compares the PSDs of the ex-lignin kerogen model at equilibrium (H/C $=0.5$ ), the ex-cellulose model at $\mathrm{H} / \mathrm{C}=0.55$ ( $i$. e., after the $1^{\text {st }} \mathrm{REMD}$ simulation, fluid removal and relaxation) and the ex-cellulose model at equilibrium $(\mathrm{H} / \mathrm{C}=0.5)$. As expected from its high porous fraction (45\%), the ex-lignin exhibits a wide PSD, with pore sizes up to $1.6 \mathrm{~nm}$. Conversely, the low-porosity ex-cellulose kerogen only counts ultramicropores with sizes below 0.8 and $0.6 \mathrm{~nm}$ at $\mathrm{H} / \mathrm{C}=0.55$ and 0.5 , respectively. The calculated PSDs, 
especially the one of the ex-lignin kerogen, correlate well with measurements made by Bousige et al. ${ }^{12}$ on type II kerogen who observed micropores in the 0.4-1.2 $\mathrm{nm}$ range. The presence of mesopores (i $2 \mathrm{~nm})$ is also expected in kerogen ${ }^{22}$ and not observed in our models. We suppose here that mesopores would require a much larger simulation cell to be obtained.

\section{Conclusion}

Using REMD together with ReaxFF, we have been able to simulate the full evolution of two important constituents of type III OM, cellulose and lignin, towards mature kerogen, demonstrating the applicability of the method to investigate the atomic scale mechanisms of extremely complex geochemical processes taking place over million years timescales. REMD predictions for the mass yields of kerogen and fluid phase compare well with the yields of solid and fluid residues obtained in lab pyrolysis experiments, despite slightly different pyrolysis conditions, and especially the absence of fluid confinement in the experiments. Especially, we have shown that twice as much kerogen and about 5-6 times more methane are obtained with lignin than with cellulose. More generally, apart from $\mathrm{CO}_{2}$, the nature and quantities of the main produced fluid molecules are also found in good agreement. Despite the very different kerogen yields obtained, the evolution paths of the two kerogens are very similar. They also compare reasonably well to data from natural samples in the sense that they are overall found in the right location of the Van Krevelen diagram for type III OM, compared for instance to type I or type II OM which would have considerably larger H/C at given O/C. A better agreement with natural type III samples would certainly require including

other constituents of type III OM like resins, waxes, saps, etc... and other chemical and biological agents like bacteria, confined water or metal catalysts.

While the two considered precursors show almost identical evolution paths and structures, in terms of composition and covalent bonding, they present very different porosities. We have indeed observed that ex-cellulose kerogen can only coalesce after a kerogen/fluid separation, 
leading to a dense ultramicroporous solid which eventually develops stiffness during further maturation. With lignin as a precursor, a kerogen with a 3D connected skeleton grows and maturates around the fluid, giving rise to an important porosity. This highlights some important effect of the detailed nature of the parent $\mathrm{OM}$ on the kerogen texture.

Finally, another important outcome from this work is that a series of atomistic kerogen models are now available for investigations at the nanoscale and possibly upscaling to shale gas extraction models. This includes the models presented in Fig. 9 and Fig. 10 as well as other structural models taken at intermediate maturities or from higher temperature replicas.

\section{Acknowledgements}

This work was supported by the Game-Changer Shell project enabled through MIT Energy Initiative and by CNRS and Aix-Marseille University foundation (AMIDEX). It was granted access to the HPC resources of [TGCC/CINES/IDRIS] under the allocation 2016A0040910065 made by GENCI (Grand Equipement National de Calcul Intensif). Some of the MD simulations presented here were also performed using the facilities of the Mésocentre de Calcul Intensif en Aquitaine (MCIA). ACTvD acknowledges support from the Multi-Scale Fluid-Solid Interactions in Architected and Natural Materials (MUSE), an Energy Frontier Research Center funded by the U.S. Department of Energy, Office of Science, Basic Energy Sciences under Award \#DESC0019285 for ReaxFF force field development for carbon-based materials. JML gratefully acknowledges Philippe Aurel for his help with the structural analysis codes.

\section{References}

(1) Sovacool, B. K. Cornucopia or curse? Reviewing the costs and benefits of shale gas hydraulic fracturing (fracking). Renew. Sustain. Energy Rev. 2014, 37, 249-264. 
(2) Yuan, J.; Luo, D.; Feng, L. A review of the technical and economic evaluation techniques for shale gas development. Appl. Energy 2015, 148, 49-65.

(3) Osborn, S. G.; Vengosh, A.; Warner, N. R.; Jackson, R. B. Methane contamination of drinking water accompanying gas-well drilling and hydraulic fracturing. Proc. Nat. Ac. Sci. USA 2011, 108, 8172-8176.

(4) Howarth, R. W.; Ingraffea, A.; Engelder, T. Natural gas: should fracking stop? Nature 2011, 477, 271-275.

(5) Vidic, R. D.; Brantley, S. L.; Vandenbossche, J. M.; Yoxtheimer, D.; Abad, J. D. Impact of Shale Gas Development on Regional Water Quality. Science 2013, 340, 1235009.

(6) Hubbert, M. K.; Willis, D. G. Mechanics Of Hydraulic Fracturing. Transactions of Society of Petroleum Engineers of AIME 1957, 210, 153-168.

(7) Middleton, R. S.; Carey, J. W.; Currier, R. P.; Hyman, J. D.; Kang, Q.; Karra, S.; Jiménez-Martínez, J.; Porter, M. L.; Viswanathan, H. S. Shale gas and non-aqueous fracturing fluids: Opportunities and challenges for supercritical CO2. Appl. Energy 2015, 147, 500-509.

(8) Kim, T. H.; Cho, J.; Lee, K. S. Evaluation of CO2 injection in shale gas reservoirs with multi-component transport and geomechanical effects. Appl. Energy 2017, 190, 1195-1206.

(9) Kerr, R. A. Natural Gas From Shale Bursts Onto the Scene. Science 2010, 328, 16241626.

(10) Cueto-Felgueroso, L.; Juanes, R. Forecasting long-term gas production from shale. Proc. Nat. Ac. Sci. USA 2013, 110, 19660-19661.

(11) Vandenbroucke, M.; Largeau, C. Kerogen origin, evolution and structure. Org. Geochem. 2007, 38, $719-833$. 
(12) Bousige, C.; Ghimbeu, C. M.; Vix-Guterl, C.; Pomerantz, A. E.; Suleimenova, A.; Vaughan, G.; Garbarino, G.; Feygenson, M.; Wildgruber, C.; Ulm, F.-J.; Pellenq, R. J. M.; Coasne, B. Realistic molecular model of kerogen's nanostructure. Nat. Mater. 2016, $15,576-582$.

(13) Obliger, A.; Valdenaire, P.-L.; Capit, N.; Ulm, F. J.; Pellenq, R. J.-M.; Leyssale, J.M. Poroelasticity of Methane-Loaded Mature and Immature Kerogen from Molecular Simulations. Langmuir 2018, 34, 13766-13780.

(14) Collell, J.; Galliero, G.; Vermorel, R.; Ungerer, P.; Yiannourakou, M.; Montel, F.; Pujol, M. Transport of Multicomponent Hydrocarbon Mixtures in Shale Organic Matter by Molecular Simulations. J. Phys. Chem. C 2015, 119, 22587-22595.

(15) Ho, T. A.; Criscenti, L. J.; Wang, Y. Nanostructural control of methane release in kerogen and its implications to wellbore production decline. Sci. Rep. 2016, 6, 28053.

(16) Ho, T. A.; Wang, Y.; Criscenti, L. J. Chemo-mechanical coupling in kerogen gas adsorption/desorption. Phys. Chem. Chem. Phys 2018, 20, 12390.

(17) Pathak, M.; Huang, H.; Meakin, P.; Deo, M. Molecular investigation of the interactions of carbon dioxide and methane with kerogen: Application in enhanced shale gas recovery. J. Nat. Gas Sci. Eng. 2018, 51, 1-8.

(18) Wu, T.; Firoozabadi, A. Effect of Microstructural Flexibility on Methane Flow in Kerogen Matrix by Molecular Dynamics Simulations. J. Phys. Chem. C 2019, 123, 1087410880.

(19) Lee, T.; Bocquet, L.; Coasne, B. Activated desorption at heterogeneous interfaces and long-time kinetics of hydrocarbon recovery from nanoporous media. Nat. Commun. 2016, 7, 11890. 
(20) Obliger, A.; Pellenq, R.; Ulm, F.-J.; Coasne, B. Free Volume Theory of Hydrocarbon Mixture Transport in Nanoporous Materials. J. Phys. Chem. Lett. 2016, 7, 3712-3717.

(21) Obliger, A.; Valdenaire, P.-L.; Ulm, F.-J.; Pellenq, R. J.-M.; Leyssale, J.-M. Methane Diffusion in a Flexible Kerogen Matrix. J. Phys. Chem. B 2019, 123, 5635-5640.

(22) Berthonneau, J.; Obliger, A.; Valdenaire, P.-L.; Grauby, O.; Ferry, D.; Chaudanson, D.; Levitz, P.; Kim, J. J.; Ulm, F.-J.; Pellenq, R. J.-M. Mesoscale structure, mechanics, and transport properties of source rocks' organic pore networks. Proc. Nat. Ac. Sci. USA 2018, 115, 12365-12370.

(23) Oberlin, A.; Boulmier, J.; Villey, M. In Kerogen, Insoluble Organic Matter from Sedimentary Rocks; Durand, B., Ed.; Editions Technip: Paris, 1980; Chapter 7, pp 191-241.

(24) Béhar, F.; Vandenbroucke, M. Chemical modelling of kerogens. Org. Geochem. 1987, $11,15-24$.

(25) Siskin, M.; Scouten, C.; Rose, K.; Aczel, T.; Colgrove, S.; Pabst Jr., R. In Composition, Geochemistry and Conversion of Oil Shales; Snape, C., Ed.; Kluwer Academic Publishers: Dordrecht, 1995; pp 143-158.

(26) Vandenbroucke, M.; Largeau, C. Kerogen: from types to models of chemical structure. Oil $\mathscr{G}$ Gas Science and Technology - Rev.IFP (Institut Français du Pétrole) 2003, 38, 719-833.

(27) Faulon, J.; Vandenbroucke, M.; Drappier, J.; Behar, F.; Romero, M. 3D chemical model for geological macromolecules. Org. Geochem. 1990, 16, 981-993.

(28) Zhang, L.; LeBoeuf, E. J. A molecular dynamics study of natural organic matter: 1. Lignin, kerogen and soot. Org. Geochem. 2009, 40, 1132-1142.

(29) Orendt, A. M.; Pimienta, I. S.; Badu, S. R.; Solum, M. S.; Pugmire, R. J.; Facelli, J. C.; Locke, D. R.; Chapman, K. W.; Chupas, P. J.; Winans, R. E. Three-Dimensional 
Structure of the Siskin Green River Oil Shale Kerogen Model: A Comparison between Calculated and Observed Properties. Energy Fuels 2013, 27, 702-710.

(30) Ungerer, P.; Collell, J.; Yiannourakou, M. Molecular Modeling of the Volumetric and Thermodynamic Properties of Kerogen: Influence of Organic Type and Maturity. Energy Fuels 2015, 29, 91-105.

(31) Kelemen, S. R.; Afeworki, M.; Gorbaty, M. L.; Sansone, M.; Kwiatek, P. J.; Walters, C. C.; Freund, H.; Siskin, M.; Bence, A. E.; Curry, D. J.; Solum, M.; Pugmire, R. J.; Vandenbroucke, M.; Leblond, M.; Behar, F. Direct Characterization of Kerogen by X-ray and Solid-State 13C Nuclear Magnetic Resonance Methods. Energy $\&$ Fuels 2007, 21, 1548-1561.

(32) Collell, J.; Ungerer, P.; Galliero, G.; Yiannourakou, M.; Montel, F.; Pujol, M. Molecular Simulation of Bulk Organic Matter in Type II Shales in the Middle of the Oil Formation Window. Energy Fuels 2014, 28, 7457-7466.

(33) Obliger, A.; Ulm, F.-J.; Pellenq, R. Impact of Nanoporosity on Hydrocarbon Transport in Shales' Organic Matter. Nano Lett. 2018, 18, 832-837.

(34) van Duin, A.; Dasgupta, S.; Lorant, F.; Goddard, W. ReaxFF: A reactive force field for hydrocarbons. J. Phys. Chem. A 2001, 105, 9396-9409.

(35) Huber, G. W.; Iborra, S.; Corma, A. Synthesis of Transportation Fuels from Biomass: Chemistry, Catalysts, and Engineering. Chem. Rev. 2006, 106, 4044-4098.

(36) Zhang, L.; Xu, C. C.; Champagne, P. Overview of recent advances in thermo-chemical conversion of biomass. Energy Convers. Manage. 2010, 51, 969-982.

(37) Karagöz, S.; Tay, T.; Ucar, S.; Erdem, M. Activated carbons from waste biomass by sulfuric acid activation and their use on methylene blue adsorption. Bioresour. Technol. 2008, 99, 6214-6222. 
(38) Maneerung, T.; Liew, J.; Dai, Y.; Kawi, S.; Chong, C.; Wang, C.-H. Activated carbon derived from carbon residue from biomass gasification and its application for dye adsorption: Kinetics, isotherms and thermodynamic studies. Bioresour. Technol. 2016, 200, 350-359.

(39) Dumanll, A. G.; Windle, A. H. Carbon fibres from cellulosic precursors: a review. J. Mat. Sci. 2012, 47, 4236-4250.

(40) Ogale, A. A.; Zhang, M.; Jin, J. Recent advances in carbon fibers derived from biobased precursors. J. App. Polymer Sci. 2016, 133, 43794.

(41) Zhang, T.; Li, X.; Qiao, X.; Zheng, M.; Guo, L.; Song, W.; Lin, W. Initial Mechanisms for an Overall Behavior of Lignin Pyrolysis through Large-Scale ReaxFF Molecular Dynamics Simulations. Energy Fuels 2016, 30, 3140-3150.

(42) Zheng, M.; Wang, Z.; Li, X.; Qiao, X.; Song, W.; Guo, L. Initial reaction mechanisms of cellulose pyrolysis revealed by ReaxFF molecular dynamics. Fuel 2016, 177, 130-141.

(43) Zhang, T.; Li, X.; Guo, L. Initial Reactivity of Linkages and Monomer Rings in Lignin Pyrolysis Revealed by ReaxFF Molecular Dynamics. Langmuir 2017, 33, 11646-11657.

(44) Rismiller, S. C.; Groves, M. M.; Meng, M.; Dong, Y.; Lin, J. Water assisted liquefaction of lignocellulose biomass by ReaxFF based molecular dynamic simulations. Fuel 2018, $215,835-843$.

(45) Salmon, E.; van Duin, A. C.; Lorant, F.; Marquaire, P.-M.; Goddard III, W. A. Early maturation processes in coal. Part 2: Reactive dynamics simulations using the ReaxFF reactive force field on Morwell Brown coal structures. Org. Geochem. 2009, 40, 1195 1209.

(46) Zhan, J.-H.; Wu, R.; Liu, X.; Gao, S.; Xu, G. Preliminary understanding of initial 
reaction process for subbituminous coal pyrolysis with molecular dynamics simulation. Fuel 2014, 134, 283-292.

(47) Castro-Marcano, F.; Russo, M. F.; van Duin, A. C.; Mathews, J. P. Pyrolysis of a large-scale molecular model for Illinois no. 6 coal using the ReaxFF reactive force field. J. Anal. Appl. Pyrolysis 2014, 109, 79-89.

(48) Zheng, M.; Li, X.; Nie, F.; Guo, L. Investigation of Overall Pyrolysis Stages for Liulin Bituminous Coal by Large-Scale ReaxFF Molecular Dynamics. Energy Fuels 2017, 31, $3675-3683$.

(49) Gao, M.; Li, X.; Guo, L. Pyrolysis simulations of Fugu coal by large-scale ReaxFF molecular dynamics. Fuel Process. Technol. 2018, 178, 197-205.

(50) Liu, X.; Zhan, J.-H.; Lai, D.; Liu, X.; Zhang, Z.; Xu, G. Initial pyrolysis mechanism of oil shale kerogen with reactive molecular dynamics simulations. Energy Fuels 2015, 29, 2987-2997.

(51) Pawar, G.; Meakin, P.; Huang, H. Reactive Molecular Dynamics Simulation of Kerogen Thermal Maturation and Cross-Linking Pathways. Energy Fuels 2017, 31, 1160111614.

(52) Salmon, E.; van Duin, A. C.; Lorant, F.; Marquaire, P.-M.; Goddard, W. A. Thermal decomposition process in algaenan of Botryococcus braunii race L. Part 2: Molecular dynamics simulations using the ReaxFF reactive force field. Org. Geochem. 2009, 40, $416-427$.

(53) Zou, C.; Raman, S.; van Duin, A. C. T. Large-scale reactive molecular dynamics simulation and kinetic modeling of high-temperature pyrolysis of the Gloeocapsomorphaprisca microfossils. J. Phys. Chem. B 2014, 118, 6302-6315. 
(54) Atmani, L.; Bichara, C.; Pellenq, R. J.-M.; Van Damme, H.; van Duin, A. C. T.; Raza, Z.; Truflandier, L. A.; Obliger, A.; Kralert, P.; Ulm, F. J.; Leyssale, J.-M. From cellulose to kerogen: molecular simulation of a geological process. Chem. Sci. 2017, 8, $8325-8335$.

(55) Crestini, C.; Melone, F.; Sette, M.; Saladino, R. Milled Wood Lignin: A Linear Oligomer. Biomacromolecules 2011, 12, 3928-3935.

(56) Srinivasan, S. G.; Ganesh, P.; van Duin, A. C. T. Development of a ReaxFF Potential for Carbon Condensed Phases and Its Application to the Thermal Fragmentation of a Large Fullerene. J. Phys. Chem. A 2015, 119, 571-580.

(57) Shin, Y. K.; Gai, L.; Raman, S.; van Duin, A. C. T. Development of a ReaxFF Reactive Force Field for the Pt-Ni Alloy Catalyst. J. Phys. Chem. A 2016, 120, 8044-8055.

(58) Tavazza, F.; Senftle, T. P.; Zou, C.; Becker, C. A.; van Duin, A. C. T. Molecular Dynamics Investigation of the Effects of Tip-Substrate Interactions during Nanoindentation. J. Phys. Chem. C 2015, 119, 13580-13589.

(59) Shinoda, W.; Shiga, M.; Mikami, M. Rapid estimation of elastic constants by molecular dynamics simulation under constant stress. Phys. Rev. B 2004, 69, 134103.

(60) Swope, W. C.; Andersen, H. C.; Berens, P. H.; Wilson, K. R. A computer simulation method for the calculation of equilibrium constants for the formation of physical clusters of molecules: Application to small water clusters. J. Chem. Phys. 1982, 76, 637-649.

(61) Plimpton, S. Fast Parallel Algorithms for Short-Range Molecular Dynamics. J. Comput. Phys. 1995, 117, 1-19.

(62) Van Krevelen, D. W. Coal $3^{\text {rd }}$ edition: Typology - Physics - Chemistry - Constitution; Elsevier, 1993. 
(63) Monthioux, M.; Landais, P.; Monin, J.-C. Comparison between natural and artificial maturation series of humic coals from the Mahakam delta, Indonesia. Org. Geochem. 1985, 8, 275-292.

(64) Zheng, M.; Li, X.; Liu, J.; Wang, Z.; Gong, X.; Guo, L.; Song, W. Pyrolysis of Liulin Coal Simulated by GPU-Based ReaxFF MD with Cheminformatics Analysis. Energy \& Fuels 2014, 28, 522-534.

(65) Franzblau, D. S. Computation of ring statistics for network models of solids. Phys. Rev. $B$ 1991, 44, 4925-30.

(66) Gelb, L. D.; Gubbins, K. E. Pore Size Distributions in Porous Glasses: A Computer Simulation Study. Langmuir 1999, 15, 305-308.

(67) Valdenaire, P.-L.; Pellenq, R. J.-M.; Ulm, F. J.; van Duin, A. C. T.; Leyssale, J.-M. Timescale prediction of complex multi-barrier pathways using flux sampling molecular dynamics and 1D kinetic integration: Application to cellulose dehydration. J. Chem. Phys. 2020, 152, 024123.

(68) Qu, T.; Guo, W.; Shen, L.; Xiao, J.; K., Z. Experimental Study of Biomass Pyrolysis Based on Three Major Components: Hemicellulose, Cellulose, and Lignin. Ind. Eng. Chem. Res. 2011, 50, 10424-10433.

(69) Muley, P. D.; Henkel, C.; Abdollahi, K. K.; Marculescu, C.; Boldor, D. A critical comparison of pyrolysis of cellulose, lignin, and pine sawdust using an induction heating reactor. Energy Convers. Manage. 2016, 117, 273-280.

(70) Gagić, T.; Perva-Uzunalić, A.; Knez, Ž.; Škerget, M. Hydrothermal Degradation of Cellulose at Temperature from 200 to $300{ }^{\circ} \mathrm{C}$. Ind. Eng. Chem. Res. 2018, 57, 65766584. 
(71) Hajaligol, M. R.; Howard, J. B.; Longwell, J. P.; Peters, W. A. Product compositions and kinetics for rapid pyrolysis of cellulose. Ind. Eng. Chem. Process Des. Dev. 1982, 21, 457-465.

(72) Yang, H.; Yan, R.; Chen, H.; Lee, D. H.; Zheng, C. Characteristics of hemicellulose, cellulose and lignin pyrolysis. Fuel 2007, 86, 1781-1788.

(73) Helgeson, H. C.; Richard, L.; McKenzie, W. F.; Norton, D. L.; Schmitt, A. A chemical and thermodynamic model of oil generation in hydrocarbon source rocks. Geochim. Cosmochim. Acta 2009, 73, 594-695. 


\section{Graphical TOC Entry}

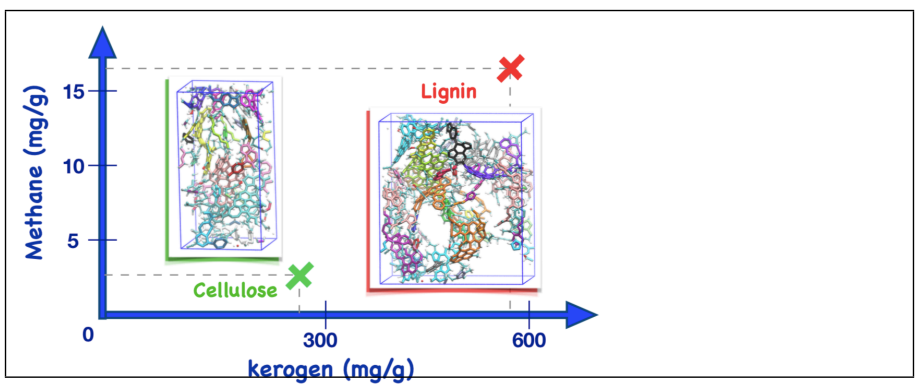

